Article

\title{
Preparation of Salen-Metal Complexes (Metal = Co or Ni) Intercalated ZnCr-LDHs and Their Photocatalytic Degradation of Rhodamine B
}

\author{
Yue Meng ${ }^{1,2}$, Wei Luo ${ }^{1}$, Shengjie $\mathrm{Xia}^{1}$ and Zheming $\mathrm{Ni}^{1, *}$ \\ 1 College of Chemical Engineering, Zhejiang University of Technology, Hangzhou 310014, China; \\ mengyue911@126.com (Y.M.); 1w717780960@163.com (W.L.); xsj63531100@163.com (S.X.) \\ 2 School of Life Sciences, Huzhou University, Huzhou 313000, China \\ * Correspondence: jchx@zjut.edu.cn; Tel.: +86-571-8832-0373 \\ Academic Editors: Shaobin Wang and Xiaoguang Duan \\ Received: 14 April 2017; Accepted: 4 May 2017; Published: 7 May 2017
}

\begin{abstract}
Salen-metal complexes (SalenM) were successfully intercalated into $\mathrm{ZnCr}$ layered double hydroxides (LDHs) through coprecipitation method, then a series of novel organic-inorganic hybrid materials were obtained. The structure and properties of the materials were thoroughly characterized by inductively-coupled plasma atomic emission spectrometry (ICP-AES), powder X-ray diffraction (XRD), Fourier transform infrared spectrometry (FTIR), scanning electron microscopy (SEM), and ultraviolet visible diffuse reflectance spectroscopy (UV-Vis DRS). Meanwhile, with Rhodamine B (RhB) as a target contaminant, the photocatalytic activities of SalenM-intercalated $\mathrm{ZnCr}$-LDHs were investigated and compared with the traditional LDHs ( $\mathrm{ZnCr}-\mathrm{LDHs}$, ZnCoCr-LDHs, and $\mathrm{ZnNiCr}-\mathrm{LDHs})$. Furthermore, the effect of the intercalation amount of SalenM (M $=\mathrm{Co}$ or $\mathrm{Ni}$ ) on the photocatalytic activity was studied. The results showed that when the molar ratio of SalenM to Cr was 0.75 , SalenM-intercalated $\mathrm{ZnCr}$-LDHs exhibited significantly higher photocatalytic activities than the traditional LDHs. The degradation rates of $\mathrm{RhB}$ reached about $90 \%$, and all of them had good recycling rates. In addition, the kinetics of photocatalytic process and the mechanism of photocatalysis are discussed.
\end{abstract}

Keywords: layered double hydroxides; Salen-metal complexes; intercalation; heterogeneous photocatalysis; Rhodamine B

\section{Introduction}

Recently, with the transformation of fiber, textile, printing, dyeing, and garment industries, the global dyeing and printing industry has developed rapidly. However, due to the development of the dyeing and printing industry, wastewater discharge has also experienced a substantial increase. At present, the treatment methods of printing and dyeing wastewater are mainly adsorption and photocatalytic degradation [1-3].

Layered double hydroxides (LDHs) are a class of anionic clay materials with octahedral layer structure. Their general formula is $\left[\mathrm{M}^{2+}{ }_{1-x} \mathrm{M}^{3+}{ }_{x}(\mathrm{OH})_{2}\right]^{x+}\left(\mathrm{A}^{n-}\right)_{x / n} \cdot \mathrm{mH}_{2} \mathrm{O}$, where $\mathrm{M}^{2+}$ and $\mathrm{M}^{3+}$ are convertible metal cations in host layers and $\mathrm{A}^{n-}$ are exchangeable anions in the channel between the host layers [4,5]. LDHs are often used as host structures for the loading of various complex anions. These materials exhibit many unique characteristics, such as large number of active alkali sites, large specific surface area, and high anion exchange capacity. They have been widely used in catalytic reactions and catalyst supports [6,7]. For the treatment of printing and dyeing wastewater, LDHs can be used as adsorbents and photocatalysts [8-11]. Because of the dual effects of surface adsorption and the interlayer adsorption of anions, LDHs can efficiently adsorb anionic contaminants in dyeing 
and printing wastewater [12]. However, the adsorption capacity of LDHs on cationic contaminants is relatively low—only a small amount of physical adsorption [13]. Moreover, the adsorption method has some disadvantages; that is, it may easily cause secondary pollution and cannot completely degrade contaminants [14]. Therefore, the photocatalytic degradation method has become a research hotspot for the treatment of cationic contaminants because of its advantages of being green non-toxic, having mild reaction conditions, high efficiency, less secondary pollution, and thorough degradation [15-17]. Rhodamine $\mathrm{B}(\mathrm{RhB})$ is one of the cationic contaminants with a carcinogenic effect on humans. It was found that the adsorption capacity and photocatalytic degradation efficiency of RhB by traditional LDHs were relatively low. In our previous work, $3 \mathrm{~g} / \mathrm{L} \mathrm{CuMgAl}-\mathrm{LDH}$ were used as catalysts to degrade $5 \mathrm{mg} / \mathrm{L} \mathrm{RhB}$ solution; the adsorption and photocatalytic degradation rates were about $30 \%$ and $50 \%$, respectively [18]. Therefore, how to introduce other highly photoactive complexes to improve the photocatalytic ability of LDHs has become our new concern. Salen-metal complexes (SalenM) with photoactive metalloporphyrin structure [19-21] can be excited by visible light, and then oxygen molecules are activated to oxidize organic contaminants [22]. Taking advantage of the exchangeability of anions in LDHs, SalenM can be intercalated into LDHs to become a class of organic-inorganic hybrid composites with supramolecular structure [23]. Such composites may become effective heterogeneous photocatalysts with synergistic effects of adsorption and photocatalysis achieving adsorption-photocatalysis-adsorption cycles. However, the study of the heterogeneous photocatalytic degradation of cationic contaminants by composite materials composed of SalenM and LDHs has so far been rarely reported [24].

In this paper, intercalated $\mathrm{ZnCr}$-LDHs with different ratios of SalenM (M = Co or Ni) to Cr were prepared by coprecipitation method. Under simulated visible light, using the typical cationic dye $\mathrm{RhB}$ as the target contaminant, the photocatalytic activities of the intercalated LDHs were studied and compared with the traditional LDHs. Meanwhile, the kinetics of photocatalysis and photocatalytic mechanism were also discussed.

\section{Results and Discussion}

\subsection{Characterization of Materials}

Inductively-coupled plasma atomic emission spectrometry (ICP-AES) analyses were performed to determine the metallic composition of the successfully-intercalated LDHs. As shown in Table 1, the experimental mole ratios of $\mathrm{Zn}: \mathrm{M}: \mathrm{Cr}(\mathrm{M}=\mathrm{Co}$ or $\mathrm{Ni})$ in the successfully intercalated LDHs were close to the prospective mole ratios of $\mathrm{Zn}: \mathrm{M}: \mathrm{Cr}(\mathrm{M}=\mathrm{Co}$ or $\mathrm{Ni})$ in the starting materials.

Table 1. The metallic composition of the successfully intercalated layered double hydroxides (LDHs).

\begin{tabular}{ccccccc}
\hline Materials & $\begin{array}{c}\text { Zn } \\
(\mathbf{p p m})\end{array}$ & $\begin{array}{c}\text { Co } \\
(\mathbf{p p m})\end{array}$ & $\begin{array}{c}\mathbf{N i} \\
\mathbf{( p p m )}\end{array}$ & $\begin{array}{c}\mathbf{C r} \\
\mathbf{( p p m )}\end{array}$ & $\begin{array}{c}\text { Experimental } \\
\text { Mole Ratios } \\
\text { (Zn:M:Cr) }\end{array}$ & $\begin{array}{c}\text { Prospective } \\
\text { Mole Ratios } \\
\text { (Zn:M:Cr) }\end{array}$ \\
\hline ZnCr-0.5SalenCo-LDHs & 21.86 & 3.13 & - & 5.52 & $3.15: 0.501: 1$ & $3: 0.50: 1$ \\
ZnCr-0.75SalenCo-LDHs & 15.08 & 3.24 & - & 3.81 & $3.15: 0.753: 1$ & $3: 0.75: 1$ \\
ZnCr-1SalenCo-LDHs & 12.95 & 3.85 & - & 3.27 & $3.15: 1.04: 1$ & $3: 1: 1$ \\
ZnCr-0.5SalenNi-LDHs & 17.69 & - & 2.50 & 4.23 & $3.33: 0.524: 1$ & $3: 0.50: 1$ \\
ZnCr-0.75SalenNi-LDHs & 15.70 & - & 3.18 & 3.75 & $3.33: 0.751: 1$ & $3: 0.75: 1$ \\
ZnCr-1SalenNi-LDHs & 13.76 & - & 3.70 & 3.28 & $3.34: 1.00: 1$ & $3: 1: 1$ \\
\hline
\end{tabular}

$\mathrm{M}=\mathrm{Co}$ or $\mathrm{Ni}$.

Figure 1A shows the XRD patterns of ZnCr-LDHs (a), ZnCoCr-LDHs (b), and ZnNiCr-LDHs (c). The obvious diffraction peaks (003), (006), (009), and (110) of curves a, b, and c in Figure 1A indicate that the synthetic traditional LDHs had typical lamellar structure $[25,26]$. The (003) lattice diffraction peaks of the traditional LDHs (a-c) appeared at $2 \theta=9.99^{\circ}-11.18^{\circ}$; thus, the interlayer distances $\left(d_{003}\right)$ were $0.79 \mathrm{~nm}$ to $0.88 \mathrm{~nm}$, which were similar to the nitrate-intercalated LDHs [27] (see Table 2). 
Figure 1B,C show the XRD patterns of $\mathrm{ZnCr}-n$ SalenCo-LDHs and $\mathrm{ZnCr}-n$ SalenNi-LDHs with different amounts of Salen-cobalt and Salen-nickel. As illustrated in Figure 1B,C, the characteristic diffraction peaks of LDHs and some other new peaks appeared. These new peaks were basically lined up with the peaks in the XRD patterns of SalenM (See Figure S1), indicating that they were derived from SalenM. Meanwhile, according to the results of ICP-AES (see Table 1), the contents of Co and Ni in the SalenM-intercalated LDHs were slightly larger than those of the prospective materials. Therefore, these new peaks in the XRD patterns of SalenM-intercalated LDHs may correspond to a small amount of SalenM which was not successfully intercalated. In addition, when the ratios of SalenM to $\mathrm{Cr}(n)$ were 0.1 and 0.25 , the (003) and (006) diffraction peaks were basically the same as those of ZnCr-LDHs (a), indicating that SalenM was not successfully intercalated. Additionally, when $n$ was greater than 0.25, the (003) and (006)-plane diffraction peaks of the intercalated LDHs had both shifted to lower angles. The intercalation of SalenM led to an increase in the interlayer distances $\left(d_{003}=1.10-1.12\right.$ $\mathrm{nm}$ ), which were significantly larger than those of the traditional LDHs (see Table 2). Subtracting the thickness of the LDHs layer $(0.48 \mathrm{~nm})$ [28], the interlayer channel heights were from $0.62 \mathrm{~nm}$ to $0.64 \mathrm{~nm}$. Then, to more clearly understand the intercalation of ZnCr- $n$ SalenM-LDHs $(n=0.5,0.75,1)$, SalenCo and SalenNi were simulated from Materials Studio 5.5 software. The calculated sizes of SalenCo and SalenNi were $1.25 \mathrm{~nm} \times 0.97 \mathrm{~nm} \times 0.56 \mathrm{~nm}$ and $1.35 \mathrm{~nm} \times 0.96 \mathrm{~nm} \times 0.38 \mathrm{~nm}$, respectively (see Figure S2). Thus, it can be inferred that the anions of SalenM are slightly inclined between the $\mathrm{ZnCr}-n$ SalenM-LDHs $(n=0.5,0.75,1)$ layers along the orientation of the short axis of SalenM.

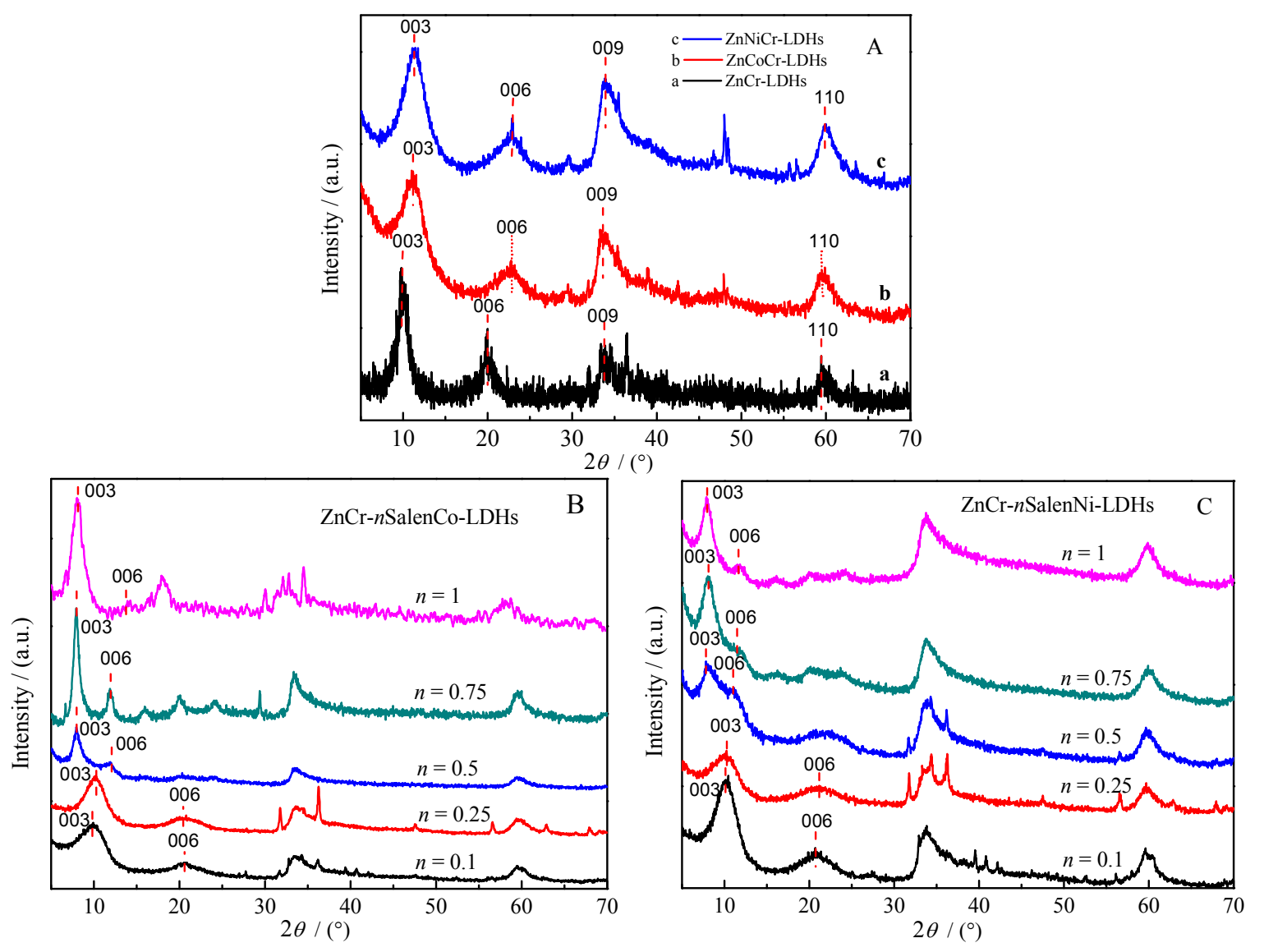

Figure 1. XRD patterns of the materials. (A) ZnCr-LDHs, ZnCoCr-LDHs, and ZnNiCr-LDHs; (B) $\mathrm{ZnCr}-n$ SalenCo-LDHs ( $n=\mathrm{Co}: \mathrm{Cr}$ ); (C) ZnCr- $n$ SalenNi-LDHs $(n=\mathrm{Ni}: \mathrm{Cr}$ ) 
Table 2. (003)-plane diffraction peak values and interlayer distance $\left(\mathrm{d}_{003}\right)$ values of the materials.

\begin{tabular}{ccclcc}
\hline Materials & $\left.\mathbf{2 \theta}_{\mathbf{0 0 3}} \mathbf{(}^{\circ}\right)$ & $\mathbf{d}_{\mathbf{0 0 3}}(\mathbf{n m})$ & \multicolumn{1}{c}{ Materials } & $\mathbf{2 \theta}_{\mathbf{0 0 3}}\left(^{\circ}\right)$ & $\mathbf{d}_{\mathbf{0 0 3}}(\mathbf{n m})$ \\
\hline ZnCr-LDHs & 9.99 & 0.89 & ZnCr-0.5SalenCo-LDHs & 7.99 & 1.11 \\
ZnCoCr-LDHs & 11.03 & 0.80 & ZnCr-0.75SalenCo-LDHs & 7.95 & 1.11 \\
ZnNiCr-LDHs & 11.18 & 0.79 & ZnCr-1SalenCo-LDHs & 8.01 & 1.10 \\
ZnCr-0.1SalenCo-LDHs & 10.00 & 0.88 & ZnCr-0.5SalenNi-LDHs & 7.91 & 1.12 \\
ZnCr-0.25SalenCo-LDHs & 10.11 & 0.87 & ZnCr-0.75SalenNi-LDHs & 7.99 & 1.11 \\
ZnCr-0.1SalenNi-LDHs & 10.42 & 0.85 & ZnCr-1SalenNi-LDHs & 7.95 & 1.11 \\
ZnCr-0.25SalenNi-LDHs & 10.41 & 0.85 & & & \\
\hline
\end{tabular}

The infrared spectra of SalenCo (a), SalenNi (b), ZnCr-LDHs (c), ZnCr-0.75SalenCo-LDHs (d), and $\mathrm{ZnCr}-0.75 \mathrm{SalenNi-LDHs}(\mathrm{e})$ are shown in Figure 2. In the IR spectra of all LDHs, the broad absorption peaks appearing at about $3400 \mathrm{~cm}^{-1}$ can be attributed to the stretching vibration of hydroxyl groups in the LDH layers and interlayer water molecules. For SalenCo (a), the characteristic absorption at $1635 \mathrm{~cm}^{-1}$ was assigned to $\mathrm{C}=\mathrm{N}$ stretching of imine bond [29]; the absorption peaks at $1400 \mathrm{~cm}^{-1}$ and $1545 \mathrm{~cm}^{-1}$ were assigned to the symmetric and asymmetric stretching vibrations of $\mathrm{C}=\mathrm{O}$ bonds of -COO- groups [30]; the disappearance of the characteristic bands at $1700-1800 \mathrm{~cm}^{-1}$ indicated that $-\mathrm{COOH}$ groups were completely deprotonated [31]. In the case of SalenNi (a), the IR spectrum was similar to that of SalenCo. For ZnCr-LDHs (c), the sharp strong absorption peak at $1380 \mathrm{~cm}^{-1}$ can be attributed to the $\mathrm{NO}_{3}{ }^{-}$stretching vibration [32], indicating that the main anion between the $\mathrm{ZnCr}-\mathrm{LDH}$ layers was $\mathrm{NO}_{3}{ }^{-}$. Then, for $\mathrm{ZnCr}-0.75$ SalenCo-LDHs (d) and $\mathrm{ZnCr}-0.75$ SalenNi-LDHs (e), the absence of the $\mathrm{NO}_{3}{ }^{-}$stretching vibration bands indicated that the intercalation processes had been completed. In addition, the characteristic absorption peaks of $\mathrm{C}=\mathrm{N}$ bonds and $-\mathrm{COO}$ - groups in the IR spectra of $\mathrm{ZnCr}-0.75 \mathrm{SalenCo}-\mathrm{LDHs}(\mathrm{d})$ and $\mathrm{ZnCr}-0.75 \mathrm{SalenNi}-\mathrm{LDHs}(\mathrm{e})$ were similar to those of SalenM (e). Meanwhile, a series of absorption peaks appearing in the IR spectra of $400-800 \mathrm{~cm}^{-1}$ may correspond to the lattice vibrations of $\mathrm{Zn}-\mathrm{O}, \mathrm{Cr}-\mathrm{O}$ bonds derived from $\mathrm{LDHs}$ and the stretching vibrations of $\mathrm{Co}-\mathrm{O}, \mathrm{Ni}-\mathrm{O}, \mathrm{Co}-\mathrm{N}, \mathrm{Ni}-\mathrm{N}$ bonds derived from SalenM $[33,34]$. Based on the above results, we can further infer that SalenM have successfully entered the LDHs interlayer.
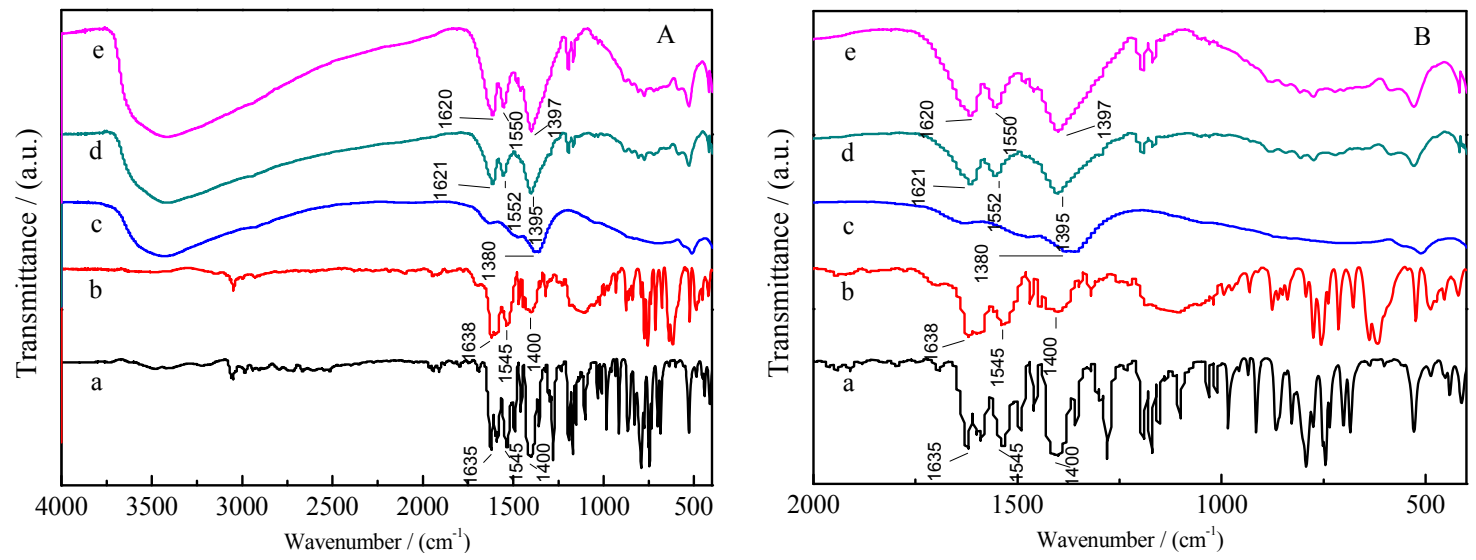

Figure 2. Fourier transform infrared (FTIR) spectra of the materials (A) Wavenumber range in 4000-400 $\mathrm{cm}^{-1}$; (B) Expand the wavenumber range in 2000-400 $\mathrm{cm}^{-1}$. a: SalenCo; b: SalenNi; c: ZnCr-LDHs; d: ZnCr-0.75SalenCo-LDHs; e: ZnCr-0.75SalenNi-LDHs.

The scanning electron microscopy (SEM) images in Figure 3 present the morphologies of $\mathrm{ZnCr}-\mathrm{LDH}$, ZnCr-0.75SalenCo-LDHs, and $\mathrm{ZnCr}-0.75 \mathrm{SalenNi-LDHs.} \mathrm{From} \mathrm{Figure} \mathrm{3a,b,} \mathrm{it} \mathrm{is}$ clear that $\mathrm{ZnCr}$-LDHs displayed a typical layered lamellar-shaped morphology of LDHs. $\mathrm{ZnCr}-0.75 \mathrm{SalenCo}-\mathrm{LDHs}$ (See Figure 3c,d) and $\mathrm{ZnCr}-0.75 \mathrm{SalenNi-LDHs}$ (See Figure 3e,f) also displayed 
layered structures similar to the pristine $\mathrm{ZnCr}-\mathrm{LDHs}$, confirming that the processes of intercalation did not change the typical morphologies of LDHs.

As is well known, the light absorption and light-induced migration of electrons and holes are the key factors in controlling the photocatalytic process [35]. The behavior of the materials in the UV-Vis diffuse reflectance indicates the photo-absorption ability. Previous studies showed that the narrowed-down band gap may lead to the enhancement of the responsiveness to visible light, as well as charge transfer and separation [36,37]. According to the literature, the band gap of the material can be calculated using the simplified Kubelka-Munk formula $E_{\mathrm{g}}=1240 / \lambda(\mathrm{nm})$ [38], where $\lambda$ is the wavelength corresponding to the absorption onset. The UV-Vis diffuse reflectance spectra of the traditional LDHs and SalenM-intercalated LDHs are shown in Figure 4. All of the LDHs presented a certain response in the visible region. The band gaps of ZnCr-LDHs, $\mathrm{ZnCoCr}-\mathrm{LDHs}$, and ZnNiCr-LDHs are $2.39 \mathrm{eV}, 2.36 \mathrm{eV}$, and $2.21 \mathrm{eV}$. While, ZnCr-0.5SalenCo-LDHs, ZnCr-0.75SalenCo-LDHs, ZnCr-1SalenCo-LDHs, ZnCr-0.5SalenNi-LDHs, ZnCr-0.75SalenNi-LDHs, and ZnCr-1SalenNi-LDHs showed narrower band gaps of $2.01 \mathrm{eV}, 1.94 \mathrm{eV}, 2.04 \mathrm{eV}, 1.93 \mathrm{eV}, 1.91 \mathrm{eV}$, and $1.97 \mathrm{eV}$, which were also narrower than other traditional photocatalytic materials such as zinc oxide [39] and titanium dioxide [40]. Therefore, the above results implied that the synergetic effect between SalenM and LDHs can narrow the band gaps and enhance the visible light harvesting of the materials, which contributed to improving their photocatalytic activities.
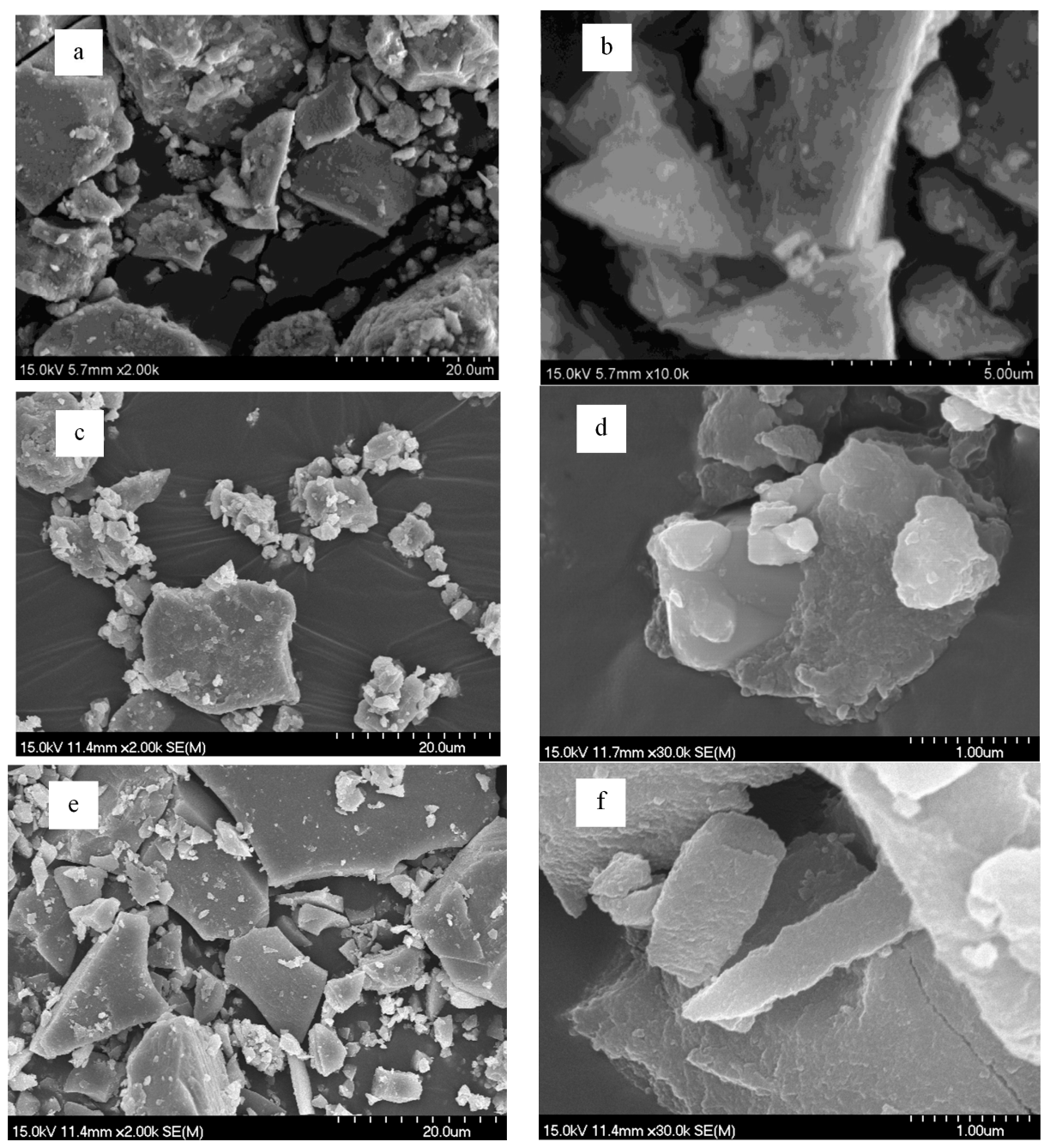

Figure 3. SEM images for ZnCr-LDHs with (a) low- and (b) high-magnification; ZnCr-0.75SalenCo-LDHs with (c) low- and (d) high-magnification; $\mathrm{ZnCr-0.75SalenNi-LDHs} \mathrm{with} \mathrm{(e)} \mathrm{low-} \mathrm{and} \mathrm{(f)} \mathrm{high-magnification.}$ 

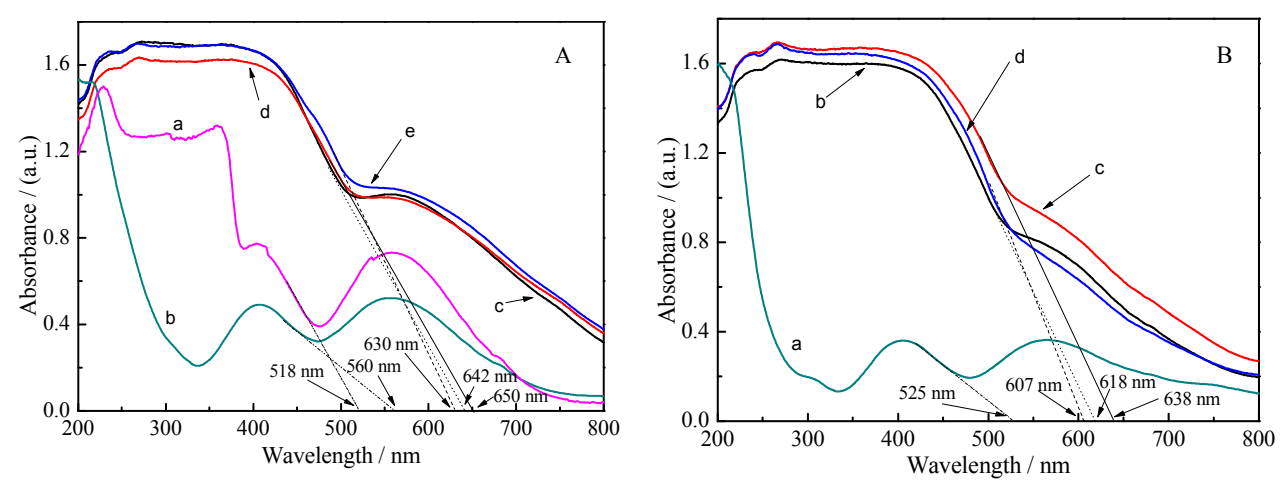

Figure 4. UV-Vis diffuse reflectance spectra of the materials. (A) a. ZnCr-LDHs; b. ZnNiCr-LDHs; c. ZnCr-0.5SalenNi-LDHs; d. ZnCr-0.75SalenNi-LDHs; e. ZnCr-1SalenNi-LDHs. (B) a. ZnCoCr-LDHs; b. ZnCr-0.5SBCo-LDHs; c. ZnCr-0.75SalenCo-LDHs; d. ZnCr-1SalenCo-LDHs.

\subsection{Photocatalytic Activity}

The photocatalytic activities of the materials were investigated by the degradation of $\mathrm{RhB}$ $(5 \mathrm{mg} / \mathrm{L})$. Figure 5 shows the results of photocatalytic activities. It can be seen that the degradation rate of blank experiment (without catalyst) is very low, showing that $\mathrm{RhB}$ is relatively stable. As shown in Figure 5, the photocatalytic activities of SalenM-intercalated LDHs were greatly improved compared with the pristine $\mathrm{ZnCr}$-LDHs. Additionally, with the increasing amount of SalenM intercalation, the degradation rates of $\mathrm{RhB}$ first increased and then decreased. The optimal ratio of intercalation was $n=0.75$ (M:Cr); after $7 \mathrm{~h}$ photodegradation, the degradation rates of $\mathrm{ZnCr}-0.75 \mathrm{SalenCo}-\mathrm{LDHs}$ and $\mathrm{ZnCr}-0.75 \mathrm{SalenNi}-\mathrm{LDHs}$ to $\mathrm{RhB}$ reached $87.9 \%$ and $91.3 \%$, respectively. When the intercalation ratio was $n=1(\mathrm{M}: \mathrm{Cr})$, the photocatalytic activities of the materials decreased. This may be because the metal complexes easily form a dimer with low activity when the ratio of intercalation is too large [41]. In addition, the metal complexes may occupy the adsorption sites on the surface of the carrier when their amount is too large [42]. This will affect the adsorption of oxygen and RhB molecules by the LDHs, thus hindering the photocatalytic reaction. At the same time, we also conducted controlled photocatalytic degradation experiments with other traditional LDHs as catalysts. When the $\mathrm{ZnCr}$-LDHs layer was doped with photosensitive metal (Co or Ni), the photocatalytic activities were not significantly improved. After $7 \mathrm{~h}$ photodegradation reaction, the degradation rates of $\mathrm{ZnCoCr}-\mathrm{LDHs}$ and $\mathrm{ZnNiCr}$-LDHs to $\mathrm{RhB}$ were only $42.10 \%$ and $45.74 \%$. Meanwhile, in similar experimental conditions, $\mathrm{ZnCr}-0.75 \mathrm{SalenCo}-\mathrm{LDH}$ and $\mathrm{ZnCr}-0.75 \mathrm{SalenNi}-\mathrm{LDH}$ s also exhibited better photocatalytic activities of $\mathrm{RhB}$ degradation than some other types of photocatalytic materials such as $\mathrm{TiO}_{2}$-diatomite composite [43], $\mathrm{CdMoO}_{4} @ \mathrm{CdS}$ [44], and $\mathrm{BiVO}_{4} / \mathrm{TiO}_{2}$ [45].
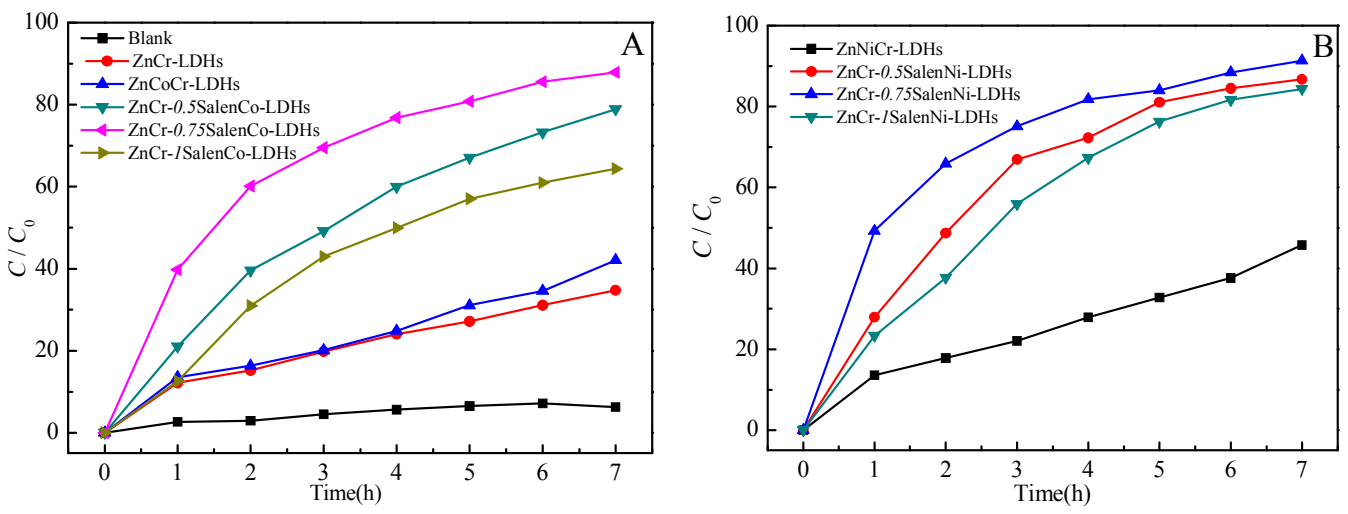

Figure 5. Photocatalytic degradation of rhodamine B (RhB) by different materials. 
The kinetic parameters of RhB photocatalytic degradation by $\mathrm{ZnCr}-0.75 \mathrm{SBCo}-\mathrm{LDHs}$, $\mathrm{ZnCr}-0.75 \mathrm{SBNi}-\mathrm{LDHs}$, and traditional LDHs were investigated based on the Langmuir-Hinshelwood model $[46,47]$. When the molecular adsorption reaches equilibrium, the reaction kinetic equation can be described as:

$$
v=-\mathrm{dC} / \mathrm{dt}=k_{\mathrm{r}} K_{\mathrm{ad}} \mathrm{C} /\left(1+K_{\mathrm{ad}} \mathrm{C}\right)
$$

where $k_{\mathrm{r}}$ is the reaction rate constant, $K_{\mathrm{ad}}$ is the adsorption equilibrium constant, and $\mathrm{C}$ is the concentration of $\mathrm{RhB}$ at time t. Since the concentration of RhB in the solution is very low and the adsorption of the material is weak $\left(K_{\mathrm{ad}} \mathrm{C}<<1\right)$, Equation (1) can be simplified as:

$$
v=-\mathrm{dC} / \mathrm{dt}=k_{\mathrm{r}} K_{\mathrm{ad}} \mathrm{C}=K_{\mathrm{app}} \mathrm{C}
$$

Integrating (2), the following equation is obtained:

$$
\ln \left(\mathrm{C}_{0} / \mathrm{C}\right)=K_{\mathrm{app}} \mathrm{t}
$$

where $\mathrm{C}_{0}$ is the concentration of RhB solution after adsorption-desorption equilibrium and $K_{\mathrm{app}}$ is the pseudo-first-order apparent rate constant. Figure 6 is the photodegradation fitted linear plot of $\mathrm{RhB}$, using $\ln \left(\mathrm{C}_{0} / \mathrm{C}\right)$ as the ordinate and light time $\mathrm{t}$ for the abscissa. It can be seen that all of the linearly-dependent coefficients are over 0.95 , so the processes of RhB degradation by $\mathrm{ZnCr}-0.75 \mathrm{SalenCo}-\mathrm{LDH}, \mathrm{ZnCr}-0.75 \mathrm{SalenNi-LDHs}$, and traditional $\mathrm{LDH}$ are consistent with pseudo-first-order kinetic model. The apparent rate constant $\left(K_{\mathrm{app}}\right)$ can be calculated from the gradient of fitted lines. In addition, the values of the $K_{\mathrm{app}}$ and the corresponding half-life $t_{1 / 2}$ are listed in Table 3 . The results showed that the reaction rates of $\mathrm{RhB}$ photocatalytic degradation by SalenM-intercalated LDHs were much higher than traditional LDHs, and they were considerably efficient.

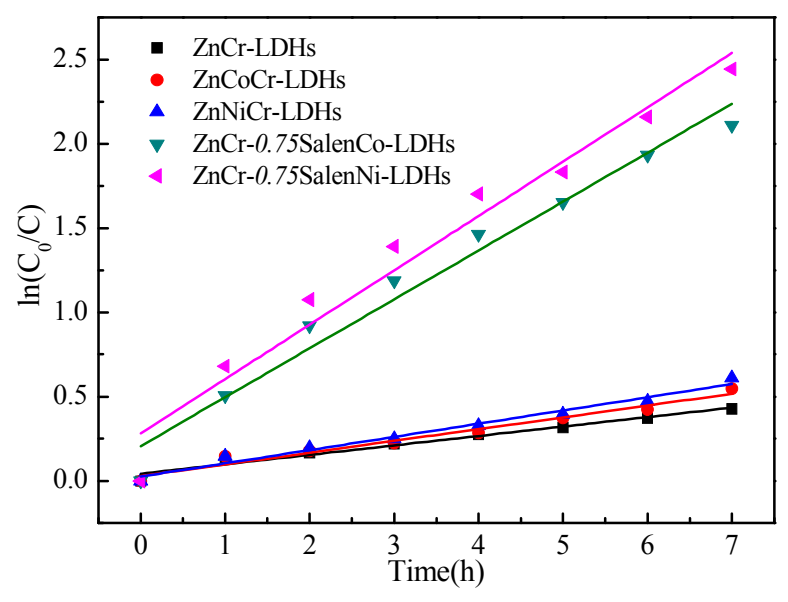

Figure 6. Pseudo-first-order kinetics degradation for RhB by different materials.

Table 3. Pseudo-first-order kinetic parameters for RhB photodegradation by different materials.

\begin{tabular}{cccc}
\hline Catalytic Materials & $\boldsymbol{K}_{\text {app }}\left(\mathbf{h}^{\mathbf{- 1}}\right)$ & $\boldsymbol{r}^{\mathbf{2}}$ & $\boldsymbol{t}_{\mathbf{1 / 2}} \mathbf{( h )}$ \\
\hline ZnCr-LDHs & 0.0560 & 0.9721 & 11.62 \\
ZnCoCr-LDHs & 0.0698 & 0.9710 & 9.61 \\
ZnNiCr-LDHs & 0.0784 & 0.9765 & 8.52 \\
ZnCr-0.75SalenCo-LDHs & 0.2902 & 0.9684 & 1.68 \\
ZnCr-0.75SalenNi-LDHs & 0.3225 & 0.9587 & 1.27 \\
\hline
\end{tabular}

Then, the activation energies of the photocatalytic reactions with $\mathrm{ZnCr}-0.75 \mathrm{SalenCo}-\mathrm{LDH}$ and $\mathrm{ZnCr}-0.75 \mathrm{SalenNi}-\mathrm{LDHs}$ as catalysts were investigated based on the results of RhB photodegradation 
at different temperatures $(288 \mathrm{~K}, 298 \mathrm{~K}, 308 \mathrm{~K})$. As shown in Figures S3 and S4, all of the linearly dependent coefficients were over 0.95 , indicating that the processes of $\mathrm{RhB}$ degradation by $\mathrm{ZnCr}-0.75$ SalenCo-LDHs and $\mathrm{ZnCr}-0.75 \mathrm{SalenNi}-\mathrm{LDH}$ at different temperatures were consistent with a pseudo-first-order kinetic model. Therefore, the values of activation energies can be calculated by Arrhenius equation:

$$
K_{\mathrm{app}}=A \exp \left(-E_{a} / R T\right)
$$

where $A$ is the pre-exponential factor, $E_{a}$ is the apparent activation energy, $R$ is the universal gas constant, $T$ is the absolute temperature. Taking the natural logarithm of the Arrhenius equation, the following equation is obtained:

$$
\ln K_{\text {app }}=-E_{a} / R T+\ln A
$$

Figure 7 shows the Arrhenius plots for RhB photodegradation by $\mathrm{ZnCr}-0.75 \mathrm{SalenCo}-\mathrm{LDH}$ and $\mathrm{ZnCr}-0.75 \mathrm{SalenNi-LDHs}$, in which $\ln K_{\text {app }}$ demonstrates a good linear dependence relation with $\mathrm{T}^{-1}$. Based on the slopes of the Arrhenius plots, the apparent activation energies $\left(E_{\mathrm{a}}\right)$ were 17.32 $\mathrm{kJ} / \mathrm{mol}$ and $15.63 \mathrm{~kJ} / \mathrm{mol}$, respectively. It was apparent that the RhB photodegradation tests by $\mathrm{ZnCr}-0.75 \mathrm{SalenCo-LDHs}$ and $\mathrm{ZnCr}-0.75 \mathrm{SalenNi}-\mathrm{LDHs}$ had relatively low apparent activation energies similar to other photocatalytic reactions [48]. The low apparent activation energies also showed that the temperature had little effect on the reaction rate.

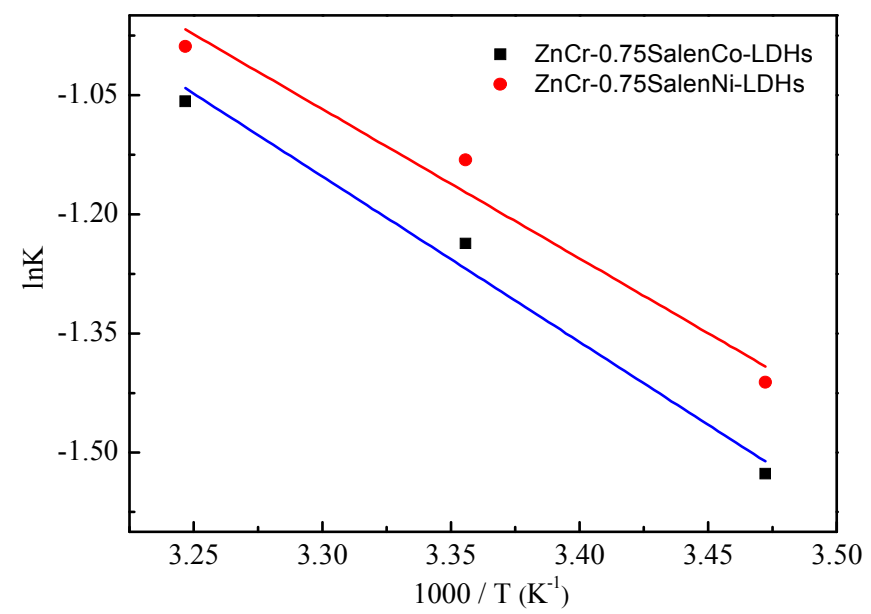

Figure 7. Arrhenius plots for RhB photodegradation by $\mathrm{ZnCr}-0.75$ SalenCo-LDHs and ZnCr-0.75SalenNi-LDHs.

\subsection{Recycling of Catalytic Materials}

In practical application, the photocatalytic stability of catalytic materials is of great significance. Traditional photocatalytic materials such as some $\mathrm{TiO}_{2}$-based materials are restricted in their application because they are easily deactivated and are difficult to recover effectively during photocatalysis [49]. To study the stability and recyclability of the catalytic materials, $\mathrm{ZnCr}-0.75 \mathrm{SalenCo-LDHs}$ and $\mathrm{ZnCr}-0.75 \mathrm{SalenNi-LDHs}$ were collected and reused under the same experimental condition. The XRD patterns of $\mathrm{ZnCr}-0.75 \mathrm{SalenM}-\mathrm{LDH} s(\mathrm{M}=\mathrm{Co}$ or $\mathrm{Ni}$ ) before and after four cycles of photodegradation tests are shown in Figure 8. It was obvious that the characteristic diffraction peaks of the recycled materials differ negligibly from the corresponding peaks of the fresh materials. Therefore, the well-ordered layered structures of $\mathrm{ZnCr}-0.75 \mathrm{SalenM}-\mathrm{LDH}$ were retained after four cycles of photocatalytic tests, suggesting that the materials were stable. Figure 9 shows the photocatalytic results of four successive cycles of the materials. The photodegradation rates of $\mathrm{RhB}$ by $\mathrm{ZnCr}-0.75 \mathrm{SalenCo}-\mathrm{LDH}$ and $\mathrm{ZnCr}-0.75 \mathrm{SalenNi-LDHs}$ decreased $13.1 \%$ and $13.4 \%$, respectively. It was obvious that the photocatalytic activities of $\mathrm{ZnCr}-0.75 \mathrm{SalenCo}-\mathrm{LDHs}$ and $\mathrm{ZnCr}-0.75 \mathrm{SalenNi}-\mathrm{LDHs}$ 
were not significantly reduced after four cycles. Therefore, these two materials will be potential photocatalysts with good performance, strong stability, and high reusability.

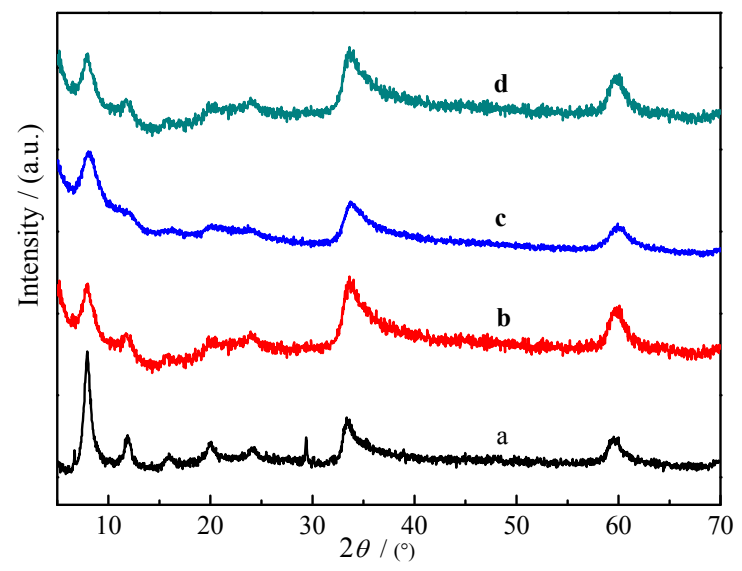

Figure 8. XRD patterns of the fresh materials and recycled materials. a: ZnCr-0.75SalenM-LDHs; b: recycled $\mathrm{ZnCr}-0.75 \mathrm{SalenM}-\mathrm{LDH}$ after four cycles of photocatalytic tests; c: ZnCr-0.75SalenM-LDHs; d: ZnCr-0.75SalenM-LDHs after four cycles of photocatalytic tests.

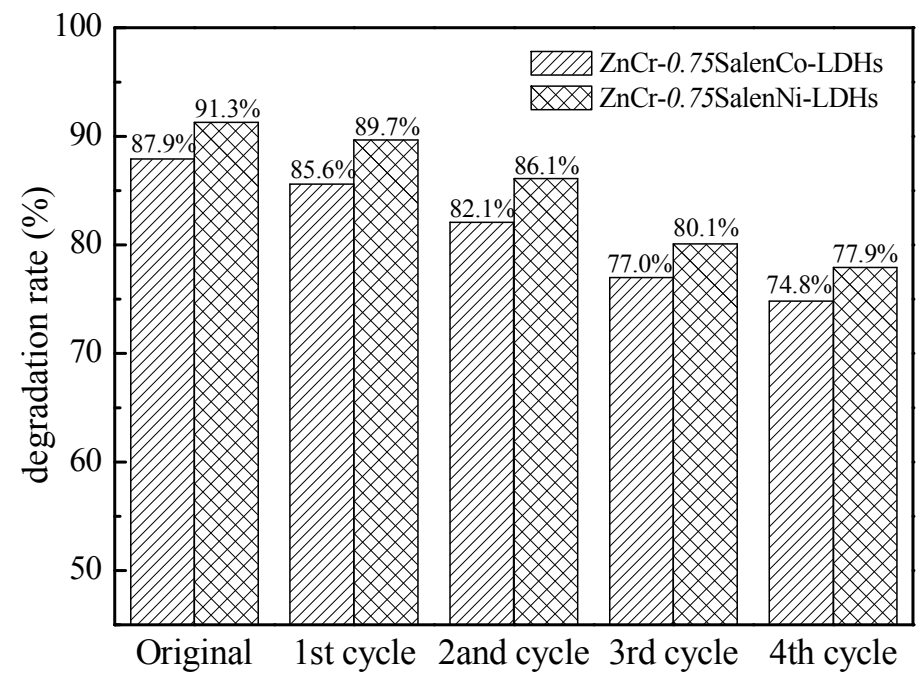

Figure 9. Comparison of RhB photocatalytic degradation by original $\mathrm{ZnCr}-0.75$ SalenM-LDHs ( $\mathrm{M}=\mathrm{Co}$ or $\mathrm{Ni}$ ) and their recycled materials.

\subsection{Mechanism of Photocatalytic Degradation}

Generally speaking, light absorption by the catalytic materials and migration of the light-induced electrons and holes are the key factors in the process of photocatalytic degradation. In the process of the photocatalytic degradation of $\mathrm{RhB}$, when $\mathrm{ZnCr}-n$ SalenM-LDHs adsorbed photons with energy larger than or equal to its band gap, the excited valance band electrons transitioned to conduction band-forming electrons $\left(\mathrm{e}_{\mathrm{CB}}{ }^{-}\right)$and holes $\left(\mathrm{h}_{\mathrm{VB}}{ }^{+}\right)$(Equation 6). The photogenerated electrons $\left(\mathrm{e}_{\mathrm{CB}}{ }^{-}\right)$ reacted with dissolved oxygen to produce $\cdot \mathrm{O}_{2}{ }^{-}$radicals (Equation 7). Meanwhile, the photogenerated holes $\left(\mathrm{h}_{\mathrm{VB}}{ }^{+}\right)$further reacted with $\mathrm{H}_{2} \mathrm{O}$ or $\mathrm{OH}^{-}$to produce $\cdot \mathrm{OH}$ radicals (Equation 8). Then, these active species $\left(\bullet \mathrm{O}_{2}{ }^{-}\right.$and $\left.\bullet \mathrm{OH}\right)$ interacted with $\mathrm{RhB}$ to carry out a redox reaction (Equation 9). In addition, part of the photogenerated holes $\left(\mathrm{h}_{\mathrm{VB}}+\right.$ ) can also directly oxidize RhB (Equation 10) [50-52].

$$
\mathrm{LDHs}+h v \rightarrow \mathrm{e}_{\mathrm{CB}}{ }^{-}+\mathrm{h}_{\mathrm{VB}}{ }^{+}
$$




$$
\begin{gathered}
\mathrm{e}_{\mathrm{CB}}^{-}+\mathrm{O} \rightarrow \mathrm{O}_{2}^{-} \\
\mathrm{h}_{\mathrm{VB}}{ }^{-}+\mathrm{H}_{2} \mathrm{O} \text { or } \mathrm{OH}^{-} \rightarrow \mathrm{OH} \\
\mathrm{O}_{2}{ }^{-}, \mathrm{OH}+\mathrm{RhB} \rightarrow \text { Derated products } \\
\mathrm{h}_{\mathrm{VB}^{+}}+\mathrm{RhB} \rightarrow \text { Derated products }
\end{gathered}
$$

It was recently reported that SalenM in visible light can be excited to transition to the excited state, and would lose electrons involved in photocatalytic degradation reaction [53]. Thus, we believed that the SalenM between the LDHs layers also played a corresponding role in the photocatalytic process. Under the excitation of visible light, SalenM turned to the excited state SalenM ${ }^{*}$ and then lost electrons, forming SalenM $\mathrm{M}^{+}$(Equation 11). The lost electrons entered the conduction band of $\mathrm{ZnCr}-n$ SalenM-LDHs (Equation 12), thus effectively suppressing the recombination of electrons and holes, and improving the photocatalytic ability. Meanwhile, Salen $\mathrm{M}^{+}$can take electrons from $\mathrm{RhB}$ to degrade it and return to SalenM (Equation 13), thereby achieving a catalytic degradation cycle [54,55]. Therefore, the photocatalytic activities of SalenM-intercalated LDHs were greatly improved compared with the traditional LDHs.

$$
\begin{aligned}
\text { SalenM }+h v \rightarrow & \text { Salen }^{*} \rightarrow \mathrm{e}^{-}+\text {Salen }^{+} \\
& \mathrm{e}^{-} \rightarrow \mathrm{e}_{\mathrm{CB}}{ }^{-} \\
\text {SalenM }{ }^{+}+\mathrm{RhB} \rightarrow & \text { SalenM }+ \text { Derated products }
\end{aligned}
$$

For clarity, the possible photocatalytic degradation mechanism by $\mathrm{ZnCr}-n \mathrm{SalenM}-\mathrm{LDHs}(\mathrm{M}=\mathrm{Co}$ or $\mathrm{Ni}$ ) is shown in Figure 10.

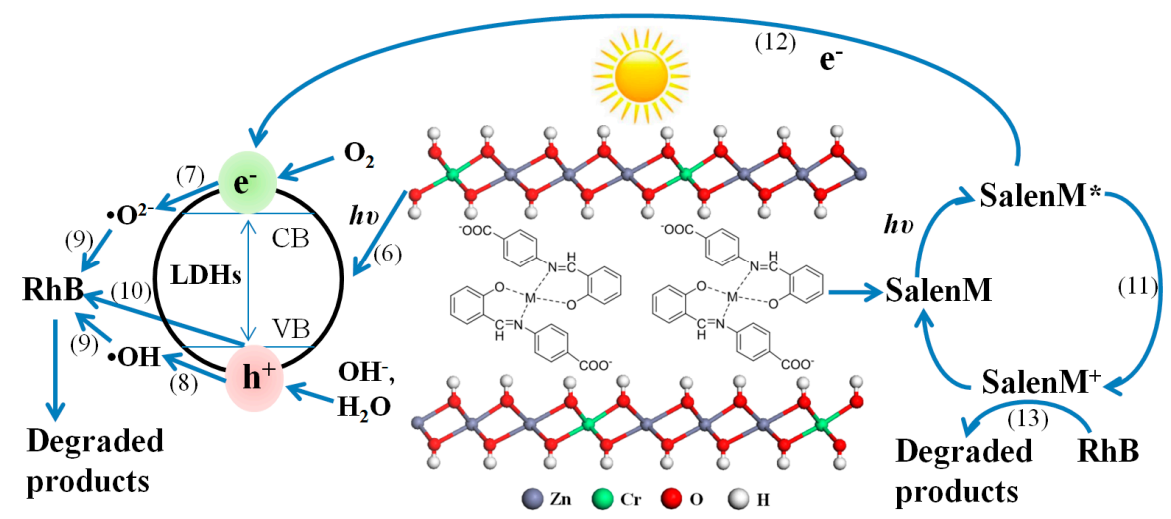

Figure 10. The possible mechanism for photocatalytic degradation of RhB by ZnCr-nSalenM-LDHs (M $=$ Co or $\mathrm{Ni})$.

\section{Materials and Methods}

\subsection{Synthesis of SalenM}

The synthesis process of SalenM is shown in Figure 11. Ethanol solution $(50 \mathrm{~mL})$ containing 50 mmol salicylaldehyde was slowly added dropwise to the ethanol solution $(100 \mathrm{~mL})$ containing 50 mmol $p$-aminobenzoic acid. After dropwise addition with continuous stirring, the reaction system was heated to reflux for $3 \mathrm{~h}$. Then, the resultant slurry was cooled, filtered, washed, and dried at 85 ${ }^{\circ} \mathrm{C}$ for $12 \mathrm{~h}$ to obtain a bright yellow needle-like Salen. Then, $6 \mathrm{mmol}$ Salen was dissolved in $100 \mathrm{~mL}$ ethanol and the $\mathrm{pH}$ was adjusted to 7.0 with $0.2 \mathrm{~mol} / \mathrm{L} \mathrm{NaOH}$ ethanol solution. After that, $10 \mathrm{~mL}$ aqueous solution containing $3 \mathrm{mmol} \mathrm{M}\left(\mathrm{CH}_{3} \mathrm{COO}\right)_{2} \cdot 4 \mathrm{H}_{2} \mathrm{O}$ was slowly added dropwise to the above 
solution. The resulting turbid solution was heated to reflux for $3 \mathrm{~h}$. Finally, the slurry was cooled, filtered, washed, and dried at $85^{\circ} \mathrm{C}$ for $12 \mathrm{~h}$ to get SalenM (M = Co or Ni).

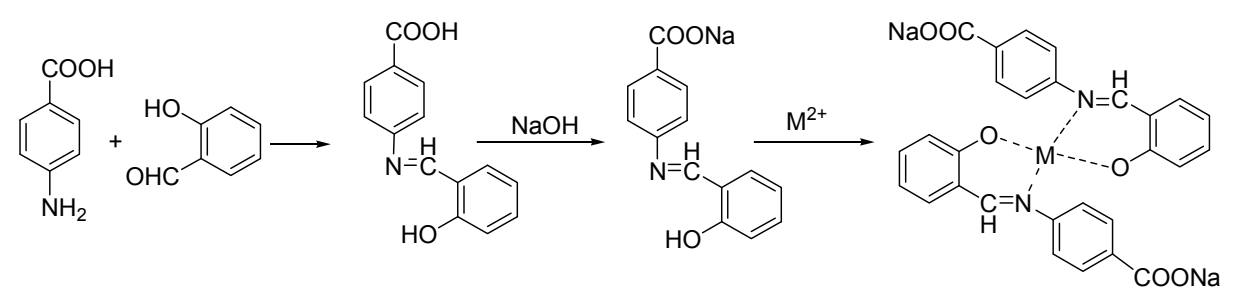

Figure 11. The preparation pathway of SalenM $(\mathrm{M}=\mathrm{Co}$ or $\mathrm{Ni})$

\subsection{Synthesis of $\mathrm{LDHs}$}

SalenM-intercalated $\mathrm{ZnCr}$-LDHs were synthesized by coprecipitation under nitrogen atmosphere. The specific synthesis process was as follows: $1 \mathrm{M} \mathrm{NaOH}$ solution and an aqueous solution $(80 \mathrm{~mL})$ containing $9.38 \mathrm{~g} \mathrm{Zn}\left(\mathrm{NO}_{3}\right)_{2} \cdot 6 \mathrm{H}_{2} \mathrm{O}$ and $4.20 \mathrm{~g} \mathrm{Cr}\left(\mathrm{NO}_{3}\right)_{3} \cdot 9 \mathrm{H}_{2} \mathrm{O}$ (initial $\mathrm{Zn}: \mathrm{Cr}=3: 1$ ) were simultaneously added dropwise to a solution $(50 \mathrm{~mL}$ ) containing SalenM (initial $\mathrm{M}: \mathrm{Cr}=0.1-1$ ) with vigorous stirring at room temperature until the final $\mathrm{pH}=9.5-10.0$. Then, the reaction system was stirred for $10 \mathrm{~h}$ and aged at $65^{\circ} \mathrm{C}$ for $24 \mathrm{~h}$. Finally, the resulting slurry was cooled, centrifuged, washed with deionized water to neutral, dried at $85^{\circ} \mathrm{C}$ for $12 \mathrm{~h}$, and ground, obtaining SalenM-intercalated $\mathrm{ZnCr}$-LDHs, marked as $\mathrm{ZnCr}-n$ SalenCo-LDHs, ZnCr- $n$ SalenNi-LDHs $(n=0.1-1)$.

Traditional LDHs (ZnCr-LDHs, ZnCoCr-LDHs, ZnNiCr-LDHs) were synthesized through the coprecipitation method under nitrogen atmosphere (initial $\mathrm{Zn}: \mathrm{Cr}=3: 1 ; \mathrm{Zn}: \mathrm{Co}: \mathrm{Cr}=3: 0.75: 1 ; \mathrm{Zn}: \mathrm{Ni}: \mathrm{Cr}$ $=3: 0.75: 1$ ). Taking $\mathrm{ZnCoCr}-\mathrm{LDH}$ as an example, the synthesis process was as follows: $1 \mathrm{M} \mathrm{NaOH}$ solution and another aqueous solution $(100 \mathrm{~mL})$ containing $75 \mathrm{mmol} \mathrm{Zn}\left(\mathrm{NO}_{3}\right)_{2} \cdot 6 \mathrm{H}_{2} \mathrm{O}, 18.75 \mathrm{mmol}$ $\mathrm{Cr}\left(\mathrm{NO}_{3}\right)_{3} \cdot 9 \mathrm{H}_{2} \mathrm{O}$, and $25 \mathrm{mmol} \mathrm{Cr}\left(\mathrm{NO}_{3}\right)_{3} \cdot 9 \mathrm{H}_{2} \mathrm{O}$ were simultaneously added dropwise to deionized water $(100 \mathrm{~mL})$ with vigorous stirring at room temperature, and the $\mathrm{pH}$ was maintained at 9-10. Then, the reaction system was stirred for 60 minutes and aged at $65^{\circ} \mathrm{C}$ for $24 \mathrm{~h}$. Finally, the resulting slurry was centrifuged, washed with deionized water to neutral, dried at $85^{\circ} \mathrm{C}$ for $12 \mathrm{~h}$, and ground, obtaining ZnCoCr-LDHs.

\subsection{Characterizations}

The contents of $\mathrm{Zn}, \mathrm{Co}, \mathrm{Ni}$, and $\mathrm{Cr}$ elements in the successfully-intercalated LDHs were determined by inductively-coupled plasma atomic emission spectrometry (ICP-AES) on an IRIS Intrepid II XSP instrument (Thermo Electron, Boston, MA, USA). Powder X-ray diffraction (PXRD) data of the prepared materials were collected on XRD-6 type diffractometer (Persee, Beijing, China) using $\mathrm{Cu}$ Ka radiation $(\lambda=0.15418 \mathrm{~nm})$ at $6 \mathrm{kV}, 20 \mathrm{~mA}$ and the scanning rate was $4^{\circ} / \mathrm{min}$ in $2 \theta$ from $5^{\circ}$ to $70^{\circ}$. Fourier transform infrared (FT-IR) spectra of the materials were obtained using a NICOLET Bruker Vector 22 (Bruker, Karlsruhe, Germany) spectrophotometer in the wavenumber range of $4000-400 \mathrm{~cm}^{-1}$. The surface morphologies of the materials were characterized by Hitachi S-4700 scanning electron microscope with an accelerating voltage of $15 \mathrm{kV}$. UV-Vis diffuse reflectance spectra (UV-Vis DRS) were measured by UV-2660 spectrophotometer (Shimadzu, Kyoto, Japan) with an integrating sphere attachment using $\mathrm{BaSO}_{4}$ as background at room temperature in air.

\subsection{Photocatalytic Degradation Performance Test}

The photocatalytic degradation performances of the materials were tested by degradation of $\mathrm{RhB}$ under simulated visible light using a $300 \mathrm{~W}$ Xenon lamp (380 $\mathrm{nm}<\lambda<760 \mathrm{~nm}$, light source is $25 \mathrm{~cm}$ from the reaction solution). Briefly, $50 \mathrm{mg}$ of catalytic material was added to a double-layer quartz reaction tube containing $50 \mathrm{~mL}$ of $5 \mathrm{mg} / \mathrm{L} \mathrm{RhB}$ solution at room temperature. Firstly, the adsorption-desorption equilibrium of RhB was achieved by stirring for $30 \mathrm{~min}$ in the dark. Then, 
the xenon lamp was turned on and the photocatalysis experiment was carried out under continuous illumination and magnetic stirring. Then, $2 \mathrm{~mL}$ aliquots were sampled and the solid phase was removed through a filter membrane every $1 \mathrm{~h}$. The absorbance of the filtrates at $554 \mathrm{~nm}$ was measured by UV-2660 spectrophotometer (Japan Shimadzu).

\section{Conclusions}

SalenM ( $\mathrm{M}=\mathrm{Co}$ or $\mathrm{Ni}$ )-intercalated $\mathrm{ZnCr}$-LDHs were successfully synthesized by facile coprecipitation method. Compared with the traditional LDHs, SalenM-intercalated ZnCr-LDHs had the advantages of narrower band gap and larger visible-light response range. These materials produced better synergistic effects of adsorption and photocatalysis and exhibited better photocatalytic degradation performances. The photodegradation reactions of RhB by all LDHs adjusted well to a pseudo-first-order kinetic behavior. In addition, the photocatalytic degradation tests of RhB were carried out from the perspective of the intercalation amount of SalenM in ZnCr-LDHs. At room temperature, the photocatalytic degradation rates of $\mathrm{RhB}$ by $\mathrm{ZnCr}-0.75 \mathrm{SBCo}-\mathrm{LDHs}$, $\mathrm{ZnCr}-0.75 \mathrm{SBNi}-\mathrm{LDH}$ reached $87.9 \%$ and $91.3 \%$, respectively. They were also very stable and had relatively high recycling rates. Therefore, this study shows that the Salen-metal complexes intercalated LDHs have potential application value in the heterogeneous photocatalytic degradation of printing and dyeing wastewater.

Supplementary Materials: The following are available online at www.mdpi.com/2073-4344/7/5/143/s1, Figure S1: XRD patterns of SalenM, Figure S2: The structures of Salen-Co and Salen-Ni, Figure S3: Pseudo-first-order kinetics degradation for RhB by ZnCr-0.75SalenCo-LDHs at different temperatures, Figure S4: Pseudo-first-order kinetics degradation for $\mathrm{RhB}$ by $\mathrm{ZnCr}-0.75 \mathrm{SalenNi-LDHs}$ at different temperatures.

Acknowledgments: This work was financed by the National Natural Science Foundation of China (21503188) and the Zhejiang Provincial Natural Science Foundation of China (LQ15B030002).

Author Contributions: Yue Meng and Shengjie Xia conceived and designed the experiments; Yue Meng performed the experiments; Yue Meng and Wei Luo performed materials characterization; Yue Meng and Shengjie Xia analyzed the data and wrote the manuscript; Zheming Ni directed the project and revised the manuscript.

Conflicts of Interest: The authors declare no conflict of interest.

\section{References}

1. Silva, T.L.; Ronix, A.; Pezoti, O.; Souza, L.S.; Leandro, P.K.T.; Bedin, K.C.; Beltrame, K.K.; Cazetta, A.L.; Almeida, V.C. Mesoporous activated carbon from industrial laundry sewage sludge: Adsorption studies of reactive dye Remazol Brilliant Blue R. Chem. Eng. J. 2016, 303, 467-476. [CrossRef]

2. Yang, C.; Wu, S.C.; Cheng J., H; Chen, Y.C. Indium-based metal-organic framework/graphite oxide composite as an efficient adsorbent in the adsorption of Rhodamine B from aqueous solution. J. Alloy. Compd. 2016, 687, 804-812. [CrossRef]

3. Dong, S.Y.; Feng, J.L.; Fan, M.H.; Pi, Y.Q.; Hu, L.M.; Han, X.; Liu, M.L.; Sun, J.Y.; Sun, J.H. Recent developments in heterogeneous photocatalytic water treatment using visible light responsive photocatalysts: A review. RSC Adv. 2015, 5, 14610-14630. [CrossRef]

4. Alessia, S.; Antonio, G.C.; Melissa, A.D.; Stefan, M.; Massimo, P.; Anna, S.; Roberto, T.; Antonio, V. Nature and reactivity of layered double hydroxides formed by coprecipitating $\mathrm{Mg}, \mathrm{Al}$ and $\mathrm{As}(\mathrm{V})$ : Effect of arsenic concentration, $\mathrm{pH}$, and aging. J. Hazard. Mater. 2015, 300, 504-512.

5. Pan, G.X.; Xia, X.H.; Luo, J.S.; Cao, F.; Yang, Z.H.; Fan, H.J. Preparation of CoAl layered double hydroxide nanoflake arrays and their high supercapacitance performance. Appl. Clay Sci. 2014, 102, $28-32$.

6. Debecker, D.P.; Gaigneaux, E.M.; Busca, Guido. Exploring, Tuning, and Exploiting the Basicity of Hydrotalcites for Applications in Heterogeneous Catalysis. Chemistry 2009, 15, 3920-3935. [CrossRef] [PubMed]

7. Urdă, A.; Popescu, I.; Cacciaguerra, T.; Tanchoux, N.; Tichit, D.; Marcu, I. Total oxidation of methane over rare earth cation-containing mixed oxides derived from LDH precursors. Appl. Catal. A Gen. 2013, 464-465, $20-27$. 
8. Kameda, T.; Uchiyama, T.; Yoshioka, T. Equilibrium and kinetics studies on the adsorption of substituted phenols by a $\mathrm{Cu}$-Al layered double hydroxide intercalated with 1-naphthol-3,8-disulfonate. J. Alloy. Compd. 2016, 670, 322-328. [CrossRef]

9. Zhang, C.; Yang, S.G.; Chen, H.Z.; He, H.; Sun, C. Adsorption behavior and mechanism of reactive brilliant red X-3B in aqueous solution over three kinds of hydrotalcite-like LDHs. Appl. Surf. Sci. 2014, 301, 329-337. [CrossRef]

10. Phuong, N.T.K.; Beak, M.; Huy, B.T.; Lee, Y. Adsorption and photodegradation kinetics of herbicide 2,4,5-trichlorophenoxyacetic acid with MgFeTi layered double hydroxides. Chemosphere 2016, 146, 51-59. [CrossRef] [PubMed]

11. Parida, K.M.; Mohapatra, L. Carbonate intercalated Zn/Fe layered double hydroxide: A novel photocatalyst for the enhanced photo degradation of azo dyes. Chem. Eng. J. 2012, 179, 131-139. [CrossRef]

12. Yan, Q.J.; Zhang, Z.; Zhang, Y.L.; Umar, A.; Guo, Z.H.; Hare, D.O.; Wang, Q. Hierarchical Fe ${ }_{3} \mathrm{O}_{4}$ Core-Shell Layered Double Hydroxide Composites as Magnetic Adsorbents for Anionic Dye Removal from Wastewater. Eur. J. Inorg. Chem. 2015, 25, 4182-4191. [CrossRef]

13. Zhang, P.; Wang, T.Q.; Qian, G.R.; Wu, D.S.; Frost, R.L. Removal of methyl orange from aqueous solutions through adsorption by calcium aluminate hydrates. J. Colloid Interf. Sci. 2014, 426, 44-47. [CrossRef] [PubMed]

14. Kurniawan, T.A.; Lo, W.H.; Chan, G.Y. Physico-chemical treatments for removal of recalcitrant contaminants from landfill leachate. J. Hazard. Mater. 2006, 129, 80-100. [CrossRef] [PubMed]

15. Habibi-Yangjeh, A.; Akhundi, A. Novel ternary $g-\mathrm{C}_{3} \mathrm{~N}_{4} / \mathrm{Fe}_{3} \mathrm{O}_{4} / \mathrm{Ag}_{2} \mathrm{CrO}_{4}$ nanocomposites: magnetically separable and visible-light-driven photocatalysts for degradation of water pollutants. J. Mol. Catal. A Chem. 2016, 415, 122-130. [CrossRef]

16. Xie, C.; Yang, S.H.; Shi, J.W.; Niu, C.M. Highly Crystallized C-Doped Mesoporous Anatase $\mathrm{TiO}_{2}$ with Visible Light Photocatalytic Activity. Catalysts 2016, 6, 117. [CrossRef]

17. Liu, F.F.; Ruxangul, J.; Wang, Y.J.; Wang, M.C.; Yang, L.; Abdiryim, T. Photodegradation of methylene blue by photocatalyst of D-A-D type polymer/functionalized multi-walled carbon nanotubes composite under visible-light irradiation. Chemosphere 2017, 168, 1669-1676. [CrossRef] [PubMed]

18. Ni, Z.M.; Xue, J.L. Synthesis of CuMgAl layered double hydroxides for efficient photocatalysis of Rhodamine B. Chem. J. Chin. Univ. 2013, 3, 503-508.

19. Jayaseeli, A.M.I.; Ramdass, A.; Rajagopal, S. Selective $\mathrm{H}_{2} \mathrm{O}_{2}$ oxidation of organic sulfides to sulfoxides catalyzed by cobalt(III)-salen ion. Polyhedron 2015, 100, 59-66. [CrossRef]

20. Matsunaga, S.; Shibasaki, M. Recent advances in cooperative bimetallic asymmetric catalysis: dinuclear Schiff base complexes. Chem. Commun. 2014, 50, 1044-1057. [CrossRef] [PubMed]

21. Hagiwara, H.; Higashi, K.; Watanabe, M.; Kakigi, R.; Ida, S.; Ishihara, T. Effect of porphyrin molecular structure on water splitting activity of a KTaO photocatalyst. Catalysts 2016, 6, 42. [CrossRef]

22. Song, Q.; Ma W, .H.; Jia, M.K.; Johnson, D.; Huang, Y.P. Degradation of organic pollutants in waters by a water-insoluble iron(III) Schiff base complex. Appl. Catal. A-Gen. 2015, 505, 70-76. [CrossRef]

23. Wang, X.L.; Shang, C.X.; Wu, G.D.; Liu, X.F.; Liu, H. Base-Free Selective Oxidation of Glycerol over LDH Hosted Transition Metal Complexes Using $3 \% \mathrm{H}_{2} \mathrm{O}_{2}$ as Oxidant. Catalysts 2016, 6, 101. [CrossRef]

24. Xia, S.J.; Liu, F.X.; Ni, Z.M.; Shi, W.; Xue, J.L.; Qian, P.P. Ti-based layered double hydroxides: Efficient photocatalysts for azo dyes degradation under visible light. Appl. Catal. B-Environ. 2014, 144, 570-579. [CrossRef]

25. Ahmed, N.; Shibata, Y.; Taniguchi, T.; Izumi, Y. Photocatalytic conversion of carbon dioxide into methanol using zinc-copper-M(III) (M = aluminum, gallium) layered double hydroxides. J. Catal. 2011, 279, 123-135. [CrossRef]

26. Prince, J.; Tzompantzi, F.; Mendoza-Damián, G.; Hernández-Beltrán, F.; Valente, J.S. Photocatalytic degradation of phenol by semiconducting mixed oxides derived from $\mathrm{Zn}(\mathrm{Ga}) \mathrm{Al}$ layered double hydroxides. Appl. Catal. B-Environ. 2015, 163, 352-360. [CrossRef]

27. Serdechnova, M.; Salak, A.N.; Barbosa, F.S.; Vieira D.E., L.; Tedim, J.; Zheludkevich, M.L.; Ferreira, M.G.S. Interlayer intercalation and arrangement of 2-mercaptobenzothiazolate and 1,2,3-benzotriazolate anions in layered double hydroxides: In situ X-ray diffraction study. J. Solid State Chem. 2016, 233, 158-165. [CrossRef] 
28. Bu, R.; Chen, F.F.; Li, J.; Li, W.; Yang, F. Adsorption capability for anionic dyes on 2-hydroxyethylammonium acetate-intercalated layered double hydroxide. Colloid. Surface. A 2016, 511, 312-319. [CrossRef]

29. Shakir, M.; Shahid, N.; Sami, N.; Azam, M.; Khan, A.U. Synthesis, spectroscopic characterization and comparative DNA binding studies of Schiff base complexes derived from L-leucine and glyoxal. Spectrochim. Acta A 2011, 82, 31-36. [CrossRef] [PubMed]

30. Kovář, P.; Pospíšil, M.; Nocchetti, M.; Čapková, P.; Melánová, K. Molecular modeling of layered double hydroxide intercalated with benzoate, modeling and experiment. J. Mol. Model. 2007, 13, 937-942.

31. Rad, F.A.; Rezvani., Z. Preparation of cubane-1,4-dicarboxylate-Zn-Al layered double hydroxide nanohybrid: Comparison of structural and optical properties between experimental and calculated results. RSC Adv. 2015, 5, 67384-67393. [CrossRef]

32. Wang, L.Y.; Wu, G.Q.; Evans, D.G. Synthesis and characterization of a layered double hydroxide containing an intercalated nickel(II) citrate complex. Mater. Chem. Phys. 2007, 104, 133-140. [CrossRef]

33. Liu, X.; Zhao, X.F.; Zhu, Y.; Zhang, F.Z. Experimental and theoretical investigation into the elimination of organic pollutants from solution by layered double hydroxides. Appl. Catal. B-Environ. 2013, 140-141, 241-248. [CrossRef]

34. Emara, A.A.A.; Ali, A.M.; El-Asmy, A.F.; Ragab, E.M. Investigation of the oxygen affinity of manganese(II), cobalt(II) and nickel(II) complexes with some tetradentate Schiff bases. J. Saudi Chem. Soc. 2014, 18, 762-773. [CrossRef]

35. Schneider, J.; Matsuoka, M.; Takeuchi, M.; Zhan, J.L.; Horiuchi, Y.; Anpo, M.; Bahnemann, D.W. Understanding $\mathrm{TiO}_{2}$ Photocatalysis: Mechanisms and Materials. Chem. Rev. 2014, 114, 9919-9986. [CrossRef] [PubMed]

36. Shimodaira, Y.; Kato, H.; Kobayashi, H.; Kudo, A. Photophysical Properties and Photocatalytic Activities of Bismuth Molybdates under Visible Light Irradiation. J. Phys. Chem. B 2006, 110, 17790-17797. [CrossRef] [PubMed]

37. Zhang, L.H.; Xiong, Z.G.; Li, L.; Burt, R.; Zhao, X.S. Uptake and degradation of Orange II by zinc aluminum layered double oxides. J. Colloid Interf. Sci. 2016, 469, 224-230. [CrossRef] [PubMed]

38. Xia, S.J.; Zhang, L.Y.; Zhou, X.B.; Shao, M.M.; Pan, G.X.; Ni, Z.M. Fabrication of highly dispersed $\mathrm{Ti} / \mathrm{ZnO}-\mathrm{Cr}_{2} \mathrm{O}_{3}$ composite as highly efficient photocatalyst for naphthalene degradation. Appl. Catal. B-Environ. 2015, 176, 266-277. [CrossRef]

39. Becker, J.; Raghupathi, K.R.; Pierre, J.S.; Zhao, D.; Koodali, R.T. Tuning of the crystallite and particle sizes of $\mathrm{ZnO}$ nanocrystalline materials in solvothermal synthesis and their photocatalytic activity for dye degradation. J. Phys. Chem. C 2011, 115, 13844-13850. [CrossRef]

40. Chiou, C.H.; Wu, C.Y.; Juang, R.S. Influence of operating parameters on photocatalytic degradation of phenol in $\mathrm{UV} / \mathrm{TiO}_{2}$ process. Chem. Eng. J. 2008, 139, 322-329. [CrossRef]

41. Huang, Y.P.; Li, J.; MA, W.H.; Chen, M.M.; Zhao, J.; Yu, J.C. Efficient $\mathrm{H}_{2} \mathrm{O}_{2}$ oxidation of organic pollutants catalyzed by supported iron sulfophenylporphyrin under visible light irradiation. J. Phys. Chem. B 2004, 108, 7263-7270. [CrossRef]

42. Li, J.; Ma, W.H.; Huang, Y.P.; Tao, X.; Zhao, J.C.; Xu, Y.M. Oxidative degradation of organic pollutants utilizing molecular oxygen and visible light over a supported catalyst of $\mathrm{Fe}(\mathrm{bpy})_{3}{ }^{2+}$ in water. Appl. Catal. B-Environ. 2004, 48, 17-24. [CrossRef]

43. Padmanabhan, S.K.; Pal, S.; Haq, E.U.; Licciulli, A. Nanocrystalline $\mathrm{TiO}_{2}$-diatomite composite catalysts: Effect of crystallization on the photocatalytic degradation of Rhodamine B. Appl. Catal. A Gen. 2014, 485, 157-162. [CrossRef]

44. Madhusudan, P.; Zhang, J.; Cheng, B.; Yu, J.G. Fabrication of $\mathrm{CdMoO}_{4} @ \mathrm{CdS}$ core-shell hollow superstructures as high performance visible-light driven photocatalysts. Phys. Chem. Chem. Phys. 2015, 17, 15339-15347. [CrossRef] [PubMed]

45. Hu, Y.; Li, D.Z.; Wang, H.B.; Zeng, G.P.; Li, X.H.; Shao, Y. Role of active oxygen species in the liquid-phase photocatalytic degradation of $\mathrm{RhB}$ using $\mathrm{BiVO}_{4} / \mathrm{TiO}_{2}$ heterostructure under visible light irradiation. J. Mol. Catal. A Chem. 2015, 408, 172-178. [CrossRef]

46. Mohapatra, L.; Parida, K.M. Zn-Cr layered double hydroxide: Visible light responsive photocatalyst for photocatalytic degradation of organic pollutants. Sep. Purif. Technol. 2012, 91, 73-80. [CrossRef] 
47. Fu, H.B.; Pan, C.S.; Yao, W.Q.; Zhu Yo., F. Visible-Light-Induced Degradation of Rhodamine B by Nanosized $\mathrm{Bi}_{2} \mathrm{WO}_{6}$. J. Phys. Chem. B 2005, 109, 22432-22439. [CrossRef] [PubMed]

48. Daneshvar, N.; Rabbani, M.; Modirshahla, N.; Behnajady, M.A. Kinetic modeling of photocatalytic degradation of Acid Red 27 in $\mathrm{UV} / \mathrm{TiO}_{2}$ process. J. Photoch. Photobio. A 2004, 168, 39-45. [CrossRef]

49. Yasui, K.; Isobe, T.; Nakajima, A. Preparation and photocatalytic activity of $\mathrm{TiO}_{2}$ powders from titanium citrate complex using two step hydrothermal treatments. Mater. Lett. 2010, 64, 2036-2039. [CrossRef]

50. Zhang, Z.H.; Zhai, S.Y.; Wang, M.H.; Ji, H.F.; He, L.H.; Ye, C.M.; Wang, C.B.; Fang, S.M.; Zhang, H.Z. Photocatalytic degradation of Rhodamine B by using a nanocomposite of cuprous oxide, three-dimensional reduced graphene oxide, and nanochitosan prepared via one-pot synthesis. J. Alloy. Compd. 2016, 659, 101-111. [CrossRef]

51. Kiantazh, F.; Habibi-Yangjeh, A. $\mathrm{Ag}_{3} \mathrm{VO}_{4} / \mathrm{ZnO}$ nanocomposites with an $\mathrm{n}-\mathrm{n}$ heterojunction as novel visible-light-driven photocatalysts with highly enhanced activity. Mat. Sci. Semicon. Proc. 2015, 39, 671-679. [CrossRef]

52. Natarajan, T.S.; Thomas, M.; Natarajan, K.; Bajaj, H.C.; Tayade, R.J. Study on UV-LED/TiO 2 process for degradation of Rhodamine B dye. Chem. Eng. J. 2011, 169, 126-134. [CrossRef]

53. O'Regan, B.C.; López-Duarte, I.; Martínez-Díaz, M.V.; Forneli, A.; Albero, J.; Morandeira, A. Catalysis of recombination and its limitation on open circuit voltage for dye sensitized photovoltaic cells using phthalocyanine dyes. J. Am. Chem. Soc. 2008, 130, 2906-2907. [CrossRef] [PubMed]

54. Chen, F.; Deng, Z.G.; Li, X.P.; Zhang, J.L.; Zhao, J.C. Visible light detoxification by 2,9,16,23-tetracarboxyl phthalocyanine copper modified amorphous titania. Chem. Phys. Lett. 2005, 415, 85-88. [CrossRef]

55. Zheng, J.J.; Jiao, Z.B. Modified $\mathrm{Bi}_{2} \mathrm{WO}_{6}$ with metal-organic frameworks for enhanced photocatalytic activity under visible light. J. Colloid Interf. Sci. 2017, 488, 234-239. [CrossRef] [PubMed]

(C) 2017 by the authors. Licensee MDPI, Basel, Switzerland. This article is an open access article distributed under the terms and conditions of the Creative Commons Attribution (CC BY) license (http://creativecommons.org/licenses/by/4.0/). 